\title{
The cost of not covering payment of treatment for Depressive Disorders
}

\section{Dear Colleagues}

In 2016 I was diagnosed with major recurrent depressive disorder (F33.2).

I used Citalopram and various evidence based nonpharmacological treatments (psycho-therapy, mindfulness, exercise and an eating plan reducing my weight from $88 \mathrm{~kg}$ $[\mathrm{BMI}=27.8]$ to $78 \mathrm{~kg}[\mathrm{BMI}=24.6])$. However my symptoms continued unabatedly, especially insomnia, daily suicidal thinking, poor concentration and decision making. Changing treatment to agomelatine (Valdoxan ${ }^{\circledR}$ ) was equally unsuccessful. In mid-2017 I then changed to bupropion (Wellbutrin ${ }^{\oplus}$ ) and a low dose of amitriptyline $(12.5 \mathrm{mg})$ with marked improvement within 48 hours. Within a week I had positive thoughts, slept well and my cognition was back to normal.

In January this year I was appointed in a permanent position as academic staff with the Faculty of Health Sciences of the University of Cape Town. With this contract I was urged to join Discovery Health. When my pharmacist sent in the prescription of my psychiatrist to claim for my medication (bupropion and amitriptyline) we were informed that Discovery Health would not cover it in line with the Council of Medical Schemes regulations on covering a defined list of 270 diagnoses and a defined list of 27 chronic conditions in terms of the Medical Schemes Act of 1998 (Act No. 131 of 1998) and its Regulations.

As a medical practitioner in the public sector who treats people with depressive disorders almost on a daily basis it came to a shock to me that in the private sector it was not the choice of medication that was not covered but the diagnosis of depressive disorders (F32 and F33) per se was not regarded as a medical condition requiring pharmacological treatment.

Can I draw your attention or remind you that in South Africa there is one suicide death every hour and between 20 and 40 attempts. ${ }^{[11}$ The lifetime prevalence for attempting suicide in South Africa is roughly three percent. ${ }^{[2]}$ Diminished sleep ( $<5$ hours/24 hours) increase the chance of suicidal attempts. ${ }^{[3]}$ Depressive disorder increases the mortality risk from suicide attempts 20 fold. ${ }^{[4]}$ Treating depressive symptoms may help suicide prevention efforts. ${ }^{[5]}$ The WHO World Health Survey studied

In South Africa, the lifetime and 12-month prevalence rates for major depressive disorder are $9.7 \%$ and $4.9 \%$ respectively, with less than a quarter of South Africans with major depressive disorder able to access services and receive treatment. ${ }^{[6]}$ Pharmacotherapy should be tailored to the individual patient. ${ }^{[7]}$ Depression is the single largest contributor to disability worldwide (contributing $7.5 \%$ of all years lived with disability in 2015). ${ }^{[8]}$ Every US\$ 1 invested in scaling up treatment for depression and anxiety leads to a return of US\$ 4 in better health and ability to work. ${ }^{[9]}$ Depression produces the greatest decrement in health compared with the chronic diseases angina, arthritis, asthma, and diabetes as found by The World Health Survey studying data from 245404 participants from 60 countries. ${ }^{[10]}$

In the light of overwhelming evidence for the health burden and mortality caused by depression and the effectiveness of pharmacological treatment, with 27 antidepressants listed in the SAMF, and in light of national policy of health for all and the constitutional right of South Africans to health care can I urge you to revisit your regulations on covering pharmacological treatment for depressive disorders?

Can I also ask you who my children, my wife and my employer should hold accountable for my untimely premature death by suicide, should I die that route?

With kind regards

\section{Dr Hermann Reuter \\ MP 0384887}

\section{References}

1. Schlebusch L. Risk factors in repeat non-fatal suicidal behaviour. S Afr J Psychol. 2005 Dec;11(3):72-4.

2. Joe $S$, Stein DJ, Seedat $S$, et al. Prevalence and correlates of non-fatal suicidal behaviour among South Africans. $\mathrm{Br} J$ Psychiatry. 2008 Apr;192(4):310-1. http://dx.doi.org/10.1192/ bjp.bp.107.037697

3. Goodwin RD, Marusic A. Association between short sleep and suicidal ideation and suicide attempt among adults in the general population. Sleep. 2008 Aug 1;31(8):1097-101.

4. Lépine $J P$, Briley $M$. The increasing burden of depression. Neuropsychiatr Dis Treat. 2011;7(Suppl 1):3-7.

5. Raubenheimer L, Jenkins LS. An evaluation of factors underlying suicide attempts in patients presenting at George Hospital emergency centre. South African Family Practice. 2015 Feb: 1 http://www.tandfonline.com/loi/ojfp20

6. Herman AA, Stein DJ, Seedat $S$, Heeringa SG, Moomal $H$, Williams DR. The South African Stress and Health (SASH) study: 12-month and lifetime prevalence of common mental disorders. S Afr Med J. 2009;99:339-44

7. Thomas E, Seedat S, The diagnosis and management of depression in the era of the DSM-5. South African Family Practice 2018; 60(1):20

8. Thomas $E$, Seedat $S$, The diagnosis and management of depression in the era of the DSM-5. South African Family Practice 2018; 60(1):20

9. WHO. Depression: let's talk. http://www.who.int/mediacentre/ news/releases/2017/world-health-day/en/ 2017 March

10. Moussavi S, Chatterji S, Verdes E, Tandon A, Patel V, Ustun B. Depression, chronic diseases, and decrements in health: results from the World Health Surveys. Lancet. 2007 Sep 8;370(9590):851-8. https://pdfs.semanticscholar.org/5915/ a079426dae3b59121ab9caa359ea9cd7de37.pdf 